\title{
Florística e ecologia das Orchidaceae das restingas do estado do Espírito Santo ${ }^{1,2}$
}

\author{
Claudio Nicoletti de Fraga ${ }^{3}$ \\ Ariane Luna Peixoto ${ }^{4}$
}

\begin{abstract}
RESUMO
Este trabalho teve como objetivo inventariar as Orchidaceae das restingas do estado do Espírito Santo, detectar as formas de vida e proceder a uma análise da similaridade entre as formações vegetais das restingas, através da flora orquidológica. As coletas de material botânico foram feitas ao longo de todo o litoral sendo incluídas as coleções dos herbários CVRD, MBML e VIES. Foram identificados 73 táxons, sendo 71 espécies, dentre estas uma nova para ciência, e dois híbridos naturais. O maior número de espécies foi encontrado em Epidendrum (7) e Pleurothallis (6). Foram encontrados 31 táxons holoepífitos, 28 táxons terrestres, 12 táxons epífitos facultativos e dois táxons hemiepífitos. Das 10 formações vegetais de restinga as Orchidaceae estiveram representadas em oito. A floresta arenosa litorânea apresentou 58 táxons, seguida pela formação aberta de Clusia (31), formação aberta de Ericaceae (20), floresta periodicamente inundada (14), formação póspraia (13), formação Palmae (10), formação brejo herbáceo (3) e formação praial graminóide (2). A maior similaridade florística, utilizando o índice de Sorensen, foi encontrada entre as formações arbustivas fechadas (pós-praia e Palmae) seguidas pelas formações arbustivas abertas (de Ericaceae e de Clusia). Estes dois grupos se ligam, com menor similaridade às formações florestais, enquanto as formações herbáceas são as mais dissimilares.
\end{abstract}

Palavras-chaves: Orchidaceae, florística, ecologia, restinga, Espírito Santo

\begin{abstract}
An inventory of the Orchidaceae of the coastal plain vegetation (restingas) of Espírito Santo State, Brazil, is presented here. The life forms were examined as well as the similarity between restinga vegetation types based on the orchid flora. Botanical material was collected along the entire coast and material from the following herbaria was examined: CVRD, MBML and VIES. A total of 73 taxa were identified, including two natural hybrids. Of the 71 remaining taxa, one was a new species. The most species-rich genera were Epidendrum (7) and Pleurothallis (6). The taxons were classified as follows: 31 holoepiphytes, 28 terrestrials, 12 facultative epiphytes and 2 hemiepiphytes. Orchid species are found in eigth of the 10 restinga vegetation types: sandy coastal forest (58), open Clusia scrub (31), open Ericaceae scrub (20), periodically flooded forest (14), closed beach-thicket (13), Palm scrub (10), sedge swamp (3) and creeping psammophytic (2). Highest floristic similarity based on Sorensen's index was found between the closed formations (beach thicket and Palmae scrub), followed by the open formations (Ericaceae and Clusia). These two groups are linked at lower similarity values with the forest formations, while the herbaceous formations are quite dissimilar.

Key words: Orchidaceae, floritics, ecology, coastal plain vegetation, Espírito Santo

${ }^{1}$ Parte da Dissertação de Mestrado apresentada à coordenação do Curso de Pós-Graduaçao em Ciências Biológicas (Botânica) da Universidade Federal do Rio de Janeiro/Museu Nacional.

${ }^{2}$ Financiamento: CNPq, Fundação O Boticário de Proteção à Natureza (FBPN), The John D. and Catherine T. MacArthur Foudation, WWF (Fundo Mundial para a Natureza) e USAID (United States Agency for International Development).

${ }^{3}$ Instituto de Pesquisas Jardim Botânico do Rio de Janeiro, Coordenadoria de Coleções Vivas, Rua Jardim Botânico, 1008, 22.470-180, Jardim Botânico, Rio de Janeiro-RJ, Brasil, cnfraga@ jbrj.gov.br

${ }^{4}$ Instituto de Pesquisas Jardim Botânico do Rio de Janeiro, Escola Nacional de Botânica Tropical, Rua Pacheco Leão,

2.040, 22.460-030, Jardim Botânico, Rio de Janeiro-RJ, Brasil, alpeixoto@terra.com.br
\end{abstract}




\section{INTRODUÇÃO}

A planície quaternária litorânea ocupa cerca de $5.000 \mathrm{~km}$ de extensão, de um total de $9.000 \mathrm{~km}$ do litoral brasileiro. É formada por acúmulo de sedimentos oriundos das últimas transgressões marítimas (Suguio \& Martin, 1990).

Os estudos botânicos na planície quaternária litorânea, para o território brasileiro, se intensificaram a partir de Ule (1901), que diferenciou algumas formações vegetais para Cabo Frio, Rio de Janeiro. No entanto, poucos trabalhos têm dedicado atenção exclusivamente às Orchidaceae das restingas brasileiras para um melhor entendimento de sua biologia e distribuição. Neste contexto, Ribeiro \& Monteiro (1994) descrevem as Orchidaceae de Picinguaba em Ubatuba, São Paulo, fornecendo lista comparativa das espécies inventariadas com as de outras regiões do litoral brasileiro. Waechter (1998) apresenta uma listagem das Orchidaceae epífitas da planície sul-rio-grandense, discutindo a ecologia do epifítismo e a distribuição geográfica para a região subtropical brasileira. Fagnani \& Siqueira (1998) apresentam uma listagem de 19 espécies de Orchidaceae para a região de Massambaba, Rio de Janeiro.

Observações para as Orchidaceae das restingas do Espírito Santo, encontram-se restritas aos trabalhos de Ruschi (1950) que, ao escrever sobre a fitogeografia do Espírito Santo, contempla um capítulo às restingas deste Estado, citando alguns gêneros e poucas espécies. Posteriormente, Ruschi (1979) dedica uma publicação exclusivamente às restingas, mencionando aí novas espécies para este ecossistema e suprimindo algumas citadas no trabalho de 1950. Ruschi (1986) inclui, em uma obra sobre as orquídeas do Espírito Santo, chave para determinação de gêneros de Orchidaceae do Estado e observações sobre a biologia da família, incluindo espécies com ocorrência nas restingas.

Nesta ultima década, as pesquisas com a flora das restingas do Espírito Santo se intensificaram, gerando novos conhecimentos sobre a presença de orquídeas. Pereira (1990a), ao descrever fitofisionomicamente a restinga do Parque Estadual de Setiba, litoral sul do Estado, inclui algumas espécies desta família. Orchidaceae é também incluída em uma lista florística para Conceição da Barra, litoral norte do Estado (Pereira \& Gomes,1994). Fabris \& Pereira (1994), mencionam a família em um levantamento florístico para a formação pós-praia da restinga de Setiba. Pereira \& Zambom (1998) citam, em uma lista florística, as espécies de Orchidaceae ocorrentes em Interlagos, Vila Velha. Pereira et al. (1998) descrevem as comunidades de uma localidade de Pontal do Ipiranga, Linhares, incluindo a família na listagem das espécies para a área. Fraga \& Pereira (1998) descrevem e ilustram oito espécies de orquídeas do pós-praia do Estado. Pereira \& Assis (2000) descrevem as comunidades de Camburi, Vitória, citando a família. Fraga (2000) apresenta dados relativos a ecologia, fitogeografia e conservação para as Orchidaceae das restingas do Espírito Santo. Pereira \& Araújo (2000) publicam a lista florística das restingas dos Estados do Rio de Janeiro e Espírito Santo, estando a família Orchidaceae incluída nesta listagem.

Mesmo com o atual avanço sobre o conhecimento das restingas do Espírito Santo, a planície quaternária litorânea do Estado ainda apresenta lacunas no que tange a levantamentos florísticos, como verificado por Mota (1991) ao mapear áreas prioritárias para o estabelecimento de novas unidades de conservação, demonstrando a necessidade de trabalhos botânicos, em áreas onde a composição florística das restingas capixabas é pouco conhecida (Fraga, 2000).

Buscando contribuir para o conhecimento das Orchidaceae nas restingas do Espírito Santo, o presente trabalho tem como objetivo oferecer um levantamento qualitativo, florístico e ecológico das Orchidaceae da restinga do Espírito Santo, detectar as formas de vida das espécies coletadas e proceder a uma análise da similaridade entre as formações vegetais deste ecossistema no Estado. 


\section{MATERIAL E MÉTODOS}

\section{Descrição e localização da área de estudo}

O litoral do Espírito Santo apresenta uma

linha de costa com cerca de $430 \mathrm{~km}$ de extensão, onde os depósitos quaternários se fazem presentes em quase toda a extensão, delimitados para o interior por platôs terciários formados pelos sedimentos continentais da Formação Barreiras ou pela região serrana composta por rochas cristalinas précambrianas. Apresenta como limites [39³0' W - $18^{\circ} 28^{\prime}$ S ] ao norte a Bahia, e ao sul [ $41^{\circ} 00^{\prime}$ $\mathrm{W}-21^{\circ} 15^{\prime}$ S] o Rio de Janeiro (Figura 1).

Os sedimentos arenosos que formam as restingas do Espírito Santo foram depositados nas últimas transgressões marítimas, há 123.000 e 5.100 anos pretéritos, representando sedimentos de origens pleistocênicas e holocênicas, respectivamente (Martin et al. 1997), ocupando cerca de 89.700 ha,

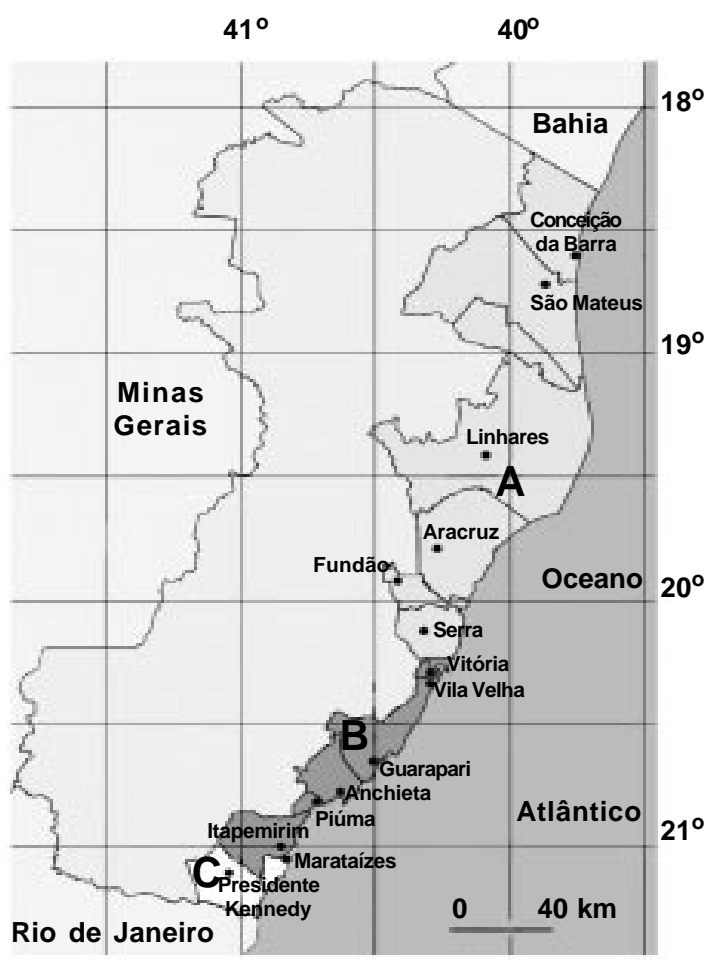

Figura 1- Regiões litorâneas do Espírito Santo, demarcados de acordo com a geomorfologia das regiões interioranas aos depósitos quaternários e a divisão em municípios do litoral do Estado (A- Litoral Norte, BLitoral Central, C- Litoral Sul). correspondendo a $1,97 \%$ do Estado. Atualmente, o ecossistema restinga ocupa 48.600 ha, o que representa $54,18 \%$ da área primária. Da área atual de restinga do Espírito Santo, 8.300 ha, o que corresponde a $17,08 \%$, encontram-se preservadas em unidades de conservação (Mota 1991).

Como observaram Martin et al. (1997), os sedimentos arenosos acabaram sendo retidos na costa continental através de armadilhas, que por vezes possibilitaram o estabelecimento de extensas planícies em algumas regiões ou somente enseadas em outras. Em função das características das unidades geomórfológicas internas às restingas e ao maior ou menor desenvolvimento dos depósitos quaternários, estes autores delimitaram cinco setores para o litoral do Espírito Santo.

No setor I, os depósitos quaternários são fracamente desenvolvidos, estando delimitados ao sopé das falésias, limitando-se da divisa com a Bahia até a cidade de Conceição da Barra (foz do Rio São Mateus). No setor II, a planície costeira atinge seu maior desenvolvimento no Estado, ficando situada de Conceição da Barra até Barra do Riacho (Aracruz), em toda área de influência do delta do Rio Doce. No setor III, o desenvolvimento dos depósitos quaternários volta a ser fraco, com o sopé das falésias chegando bem próximo ao mar, estendendo-se de Barra do Riacho até Tubarão (entrada da Bahia de Vitória). Todos estes setores da planície quaternária litorânea apresentam em comum o fato de estarem delimitados, para o interior, pelos platôs terciários da Formação Barreiras, formando o Litoral Norte do Estado do Espírito Santo (Figura 1A).

O setor IV corresponde à zona de afloramentos de rochas cristalinas précambrianas em contato direto com os depósitos quaternários, sendo caracterizado por apresentar um litoral bastante recortado, com os depósitos bem desenvolvidos nas porções côncavas e ausentes nas partes convexas, formando praias em enseadas com uma pedra 
em cada ponta. Este setor do litoral estendese da entrada da baía de Vitória até o final de Itapemirim, formando o Litoral Central do Espírito Santo (Figura 1B).

O setor V estende-se da foz do Rio Itapemirim, limite entre os municípios de Itapemirim ao norte e Marataízes ao sul, até a divisa com o Estado do Rio de Janeiro ao sul. Este setor é caracterizado por um fraco desenvolvimento, em virtude da formação de falésias na linha de praia, em Marataízes. Apresenta extensões consideráveis nos vales entalhados na Formação Barreiras em Presidente Kennedy, próximo à foz do Rio Itabapoana, formando o Litoral Sul do Estado do Espírito Santo (Figura 1C).

\section{Identificação das formações vegetais das restingas do Espírito Santo}

No Espírito Santo, as formações de restinga têm sido descritas e agrupadas de modos distintos por diversos autores. Pereira (1990a), descreveu 11 formações para o Parque Estadual Paulo César Vinha, em Setiba, Guarapari. Outra formação foi descrita por Pereira (1995) para Reserva Biológica de Comboios, Linhares, na faixa litorânea ao norte do Estado, denominada comunidade praial graminóide.

As formações halófila e psamófilareptante foram posteriormente agrupadas na comunidade halófila-psamófila por Thomaz \& Monteiro (1994), em um trabalho exclusivo de comparação entre estas formações ao longo do litoral do Estado. Pereira (1990a) também considerou outras duas formações difíceis de serem separadas em campo, mata seca e mata de Myrtaceae, que posteriormente foram consideradas por Fabris (1995) como uma só formação, denominada floresta arenosa litorânea, como já havia feito Ruschi (1950, 1979) ao usar a denominação mata esclerófila litorânea.

Das 12 formações descritas para o litoral do Espírito Santo, serão consideradas neste trabalho somente 10: halófila-psamófila (halófila e psamófila reptante), floresta arenosa litorânea (mata seca e mata de Myrtaceae), formação praial graminóide, formação brejo herbáceo, formação pós-praia, formação Palmae, formação aberta de Clusia, formação aberta de Ericaceae, floresta periodicamente inundada e floresta permanentemente inundada.

As diferenças fisionômicas da vegetação, com maior ou menor complexidade, são acompanhadas por modificações estruturais e por espécies que caracterizam cada formação, como as observadas por Pereira (1990a) e Araújo \& Henriques (1984), o que auxilia na identificação das formações no trabalho de campo.

Dentre as 10 formações vegetais, algumas apresentam vegetação predominantemente herbácea heliófila, com maior ou menor disponibilidade de água, devido a diferentes distâncias do lençol freático, como observado por Pereira et al. (1992) para a formação brejo herbáceo e Pereira (1995) para a formação praial graminóide. Outras são formadas por plantas predominantemente arbustivas, com modificações na fisionomia em virtude de poderem ser abertas ou fechadas, separando, desta forma, as formações póspraia e Palmae (arbustivas fechadas) das formações abertas de Clusia e de Ericaceae (arbustivas abertas). A diferença entre as duas arbustivas fechadas está em função da dominância de uma de suas espécies (Pereira, 1990a; Cardoso, 1995), enquanto que as diferenças entre as formações arbustivas abertas estão relacionadas, principalmente, à distância da vegetação do lençol freático, como observado por Pereira (1990a) e Pereira \& Araújo (1995).

O litoral capixaba também apresenta formações florestais, que se diferenciam principalmente em função do alagamento no decorrer do ano, em floresta arenosa litorânea, floresta periodicamente inundada e floresta permanentemente inundada. 


\section{Levantamento florístico e análise estatística}

Realizaram-se coletas de material botânico em estádio de floração e/ou frutificação, que foram preparadas para herbário segundo Mori et al. (1989), sendo os exemplares posteriormente depositados no Herbário MBML.

A identificação das espécies foi feita através de literatura especializada e comparações com exemplares dos herbários MBML, VIES, CVRD, RB, R, HB, GUA, UB, CEN, CEPEC e SP. O enquadramento em subfamílias para as espécies coletadas foi baseado em Cameron et al. (1999).

Em relação à forma de vida, as espécies foram enquadradas em holoepífitas e epífitas facultativas, baseado no tipo de relação que estabelecem com o hospedeiro de acordo com Benzing (1986), ou hemiepífitas segundo Putz \& Holbrook (1986), além de espécies terrestres de acordo com Dressler (1981). As identificações das formas de vida procederamse por visualização direta ou através de dados de coleta contidos nas etiquetas de herbário.

Após a elaboração da lista de espécies de Orchidaceae das restingas do Estado do Espírito Santo, procederam-se análises de similaridade utilizando o coeficiente de Sorensen (Muller-Dombois \& Ellenberg 1974), sendo as formações trabalhadas aos pares com base na presença/ausência das espécies, através do programa FITOPAC (Shepherd, 1984).

Para auxiliar a visualização dos grupos de espécies que mais influenciaram na união entre as diversas formações, optou-se por apresentar dendogramas de similaridade, utilizando-se o índice de Sorensen, entre as formações e as espécies de cada tipo de forma de vida (terrestre, holoepífito e epífito facultativo).

\section{RESULTADOS E DISCUSSÃO}

Foram identificados exemplares pertencentes a 73 táxons, sendo 71 espécies, dentre estas uma nova para a ciência, e dois híbridos naturais, contidos em 41 gêneros e um híbrido intergenérico, distribuídos nas subfamílias Vanilloideae (4), Orchidoideae (14) e Epidendroideae (55).

Os gêneros com maior número de espécies foram Epidendrum com sete espécies e Pleurothallis com seis espécies, seguidos por Catasetum e Habenaria com quatro espécies; Cattleya, Cyrtopodium, Oncidium, Prescottia e Sobralia com três espécies; Campylocentrum, Eltroplectris, Prosthechea e Vanilla com duas espécies. Os demais 29 gêneros encontram-se representados por uma única espécie (Tabela 1).

\section{Formas de vidas das Orchidaceae da restinga do Espírito Santo}

A forma de vida predominante (Figura 2) foi a holoepífita, encontrada em 31 espécies (42\%), seguido de 28 espécies terrestres (38\%), 12 epífitas facultativas (16\%) e de duas hemiepífitas (3\%).

As espécies holoepífitas das restingas do Espírito Santo são exclusivas da subfamília Epidendroideae. Segundo Breier (1999) as espécies com esta relação possuem adaptações para o epifitismo, passando todo seu ciclo de vida sobre um forófito, apresentando exigência quanto ao tipo de

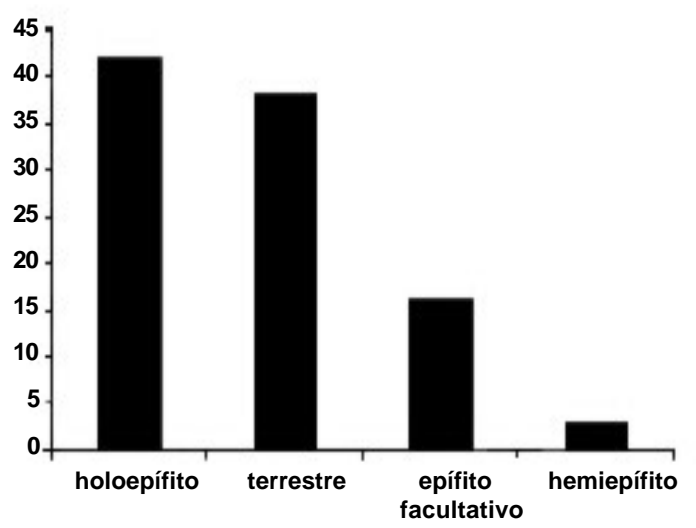

Figura 2- Porcentagem de espécies por formas de vida das Orchidaceae nas restingas do estado do Espírito Santo. 
Tabela 1- Relação das espécies de Orchidaceae das restingas do Estado do Espírito Santo assinalando-se a forma de vida (HOL- holoepífitos; EPF- epífitos facultativos; TER- terrestres; HEM- hemiepífitos) e distribuição nas formações de restinga (1- formação praial graminóide; 2- formação brejo herbáceo 3- formação pós-praia; 4- formação Palmae; 5- formação aberta de Ericaceae; 6- formação aberta de Clusia; 7- floresta arenosa litorânea; 8- floresta periodicamente inundada).

\begin{tabular}{|c|c|c|c|c|c|c|c|c|c|}
\hline \multirow[t]{3}{*}{ Espécies } & \multirow[t]{3}{*}{$\begin{array}{l}\text { Forma } \\
\text { de vida }\end{array}$} & \multicolumn{6}{|c|}{$\begin{array}{cc} & \text { Formações } \\
\text { herbáceas } & \text { arbustivas }\end{array}$} & \multirow{2}{*}{\multicolumn{2}{|c|}{ florestais }} \\
\hline & & & & \multicolumn{2}{|c|}{ fechadas } & \multicolumn{2}{|c|}{ abertas } & & \\
\hline & & 1 & 2 & 3 & 4 & 5 & 6 & 7 & 8 \\
\hline Baedlea elegans (Hoehne) Garay & TER & 0 & 0 & 0 & 0 & 0 & 0 & 1 & 1 \\
\hline Brassavola tuberculata Hook. & $\mathrm{EPF}$ & 0 & 0 & 1 & 0 & 1 & 1 & 1 & 0 \\
\hline Brassocattleya tramandahy Hort. & EPF & 0 & 0 & 1 & 0 & 0 & 1 & 0 & 0 \\
\hline $\begin{array}{l}\text { Campylocentrum aciculatum (Rchb. f. \& Warm. } \\
\text { ex Rchb. f.) Cogn. }\end{array}$ & $\mathrm{HOL}$ & 0 & 0 & 0 & 0 & 0 & 1 & 1 & 0 \\
\hline Campylocentrum micranthum (Lindl.) Rolfe & $\mathrm{HOL}$ & 0 & 0 & 1 & 0 & 0 & 1 & 1 & 1 \\
\hline Catasetum discolor (Lindl.) Lindl. & TER & 1 & 0 & 1 & 1 & 1 & 1 & 0 & 0 \\
\hline Catasetum luridum (Link.) Lindl. & HOL & 0 & 0 & 0 & 0 & 0 & 0 & 1 & 0 \\
\hline Catasetum macrocarpum Rich. ex Kunth & HOL & 0 & 0 & 0 & 0 & 0 & 0 & 1 & 0 \\
\hline Catasetum purum Nees \& Sinnings & HOL & 0 & 0 & 0 & 0 & 0 & 0 & 1 & 0 \\
\hline Cattleya guttata Lindl. & EPF & 0 & 0 & 1 & 0 & 1 & 1 & 1 & 0 \\
\hline Cattleya harrisoniana Bateman ex Lindl. & $\mathrm{EPF}$ & 0 & 0 & 0 & 0 & 0 & 1 & 1 & 0 \\
\hline Cattleya $\mathrm{x}$ duveenii Pabst \& A. F. Mello & HOL & 0 & 0 & 0 & 0 & 0 & 1 & 0 & 0 \\
\hline Cleistes revoluta (Barb. Rodr.) Schltr. & TER & 0 & 0 & 0 & 0 & 1 & 0 & 0 & 0 \\
\hline Cochleanthes wailesiana (Lindl.) Schult. \& Garay & HOL & 0 & 0 & 0 & 0 & 0 & 0 & 1 & 0 \\
\hline Coryanthes speciosa (Hook.) Hook. & HOL & 0 & 0 & 0 & 0 & 0 & 0 & 1 & 1 \\
\hline Cyrtopodium gigas (Vell.) Hoehne & HOL & 0 & 0 & 0 & 0 & 0 & 1 & 1 & 0 \\
\hline Cyrtopodium holstii L. C. Menezes & TER & 0 & 0 & 1 & 1 & 1 & 1 & 0 & 0 \\
\hline Cyrtopodium polyphyllum (Vell.) Pabst ex F. Barros & TER & 0 & 0 & 1 & 1 & 1 & 1 & 1 & 0 \\
\hline Dimerandra emarginata (G. Mey.) Hoehne & HOL & 0 & 0 & 0 & 0 & 0 & 0 & 1 & 0 \\
\hline Dryadella obrieniana (Rolfe) Luer & HOL & 0 & 0 & 0 & 0 & 0 & 0 & 1 & 0 \\
\hline Eltroplectris calcarata (Sw.) Garay \& Sweet. & TER & 0 & 0 & 1 & 1 & 1 & 1 & 1 & 1 \\
\hline Eltroplectris triloba (Lindl.) Pabst & TER & 0 & 0 & 1 & 1 & 1 & 1 & 1 & 0 \\
\hline Epidendrum coronatum Ruiz \& Pav. & HOL & 0 & 0 & 0 & 0 & 0 & 0 & 1 & 0 \\
\hline Epidendrum densiflorum Hook. & EPF & 0 & 0 & 0 & 0 & 0 & 0 & 1 & 0 \\
\hline Epidendrum denticulatum Barb. Rodr. & TER & 0 & 0 & 1 & 1 & 1 & 1 & 0 & 0 \\
\hline Epidendrum imatophyllum Lindl. & HOL & 0 & 0 & 0 & 0 & 0 & 0 & 1 & 1 \\
\hline Epidendrum latilabrum Lindl. & EPF & 0 & 0 & 0 & 0 & 0 & 1 & 1 & 0 \\
\hline Epidendrum rigidum Jacq. & HOL & 0 & 0 & 0 & 0 & 0 & 0 & 1 & 0 \\
\hline Epidendrum secundum Jacq. & TER & 0 & 0 & 0 & 0 & 0 & 1 & 0 & 0 \\
\hline Epistephium lucidum Cogn. & TER & 0 & 0 & 0 & 0 & 1 & 0 & 0 & 1 \\
\hline Galeandra stangeana Rchb. f. & HOL & 0 & 0 & 0 & 0 & 0 & 0 & 1 & 0 \\
\hline Galeottia ciliata (Morel) Dressler \& Christenson & $\mathrm{EPF}$ & 0 & 0 & 0 & 0 & 0 & 0 & 1 & 0 \\
\hline Habenaria fastor Wram. & TER & 0 & 1 & 0 & 0 & 0 & 0 & 0 & 0 \\
\hline Habenaria leptoceras Hook. & TER & 0 & 0 & 0 & 1 & 1 & 1 & 1 & 0 \\
\hline Habenaria parviflora Lindl. & TER & 0 & 1 & 0 & 0 & 0 & 0 & 0 & 0 \\
\hline Habenaria repens Nutt. & TER & 0 & 1 & 0 & 0 & 0 & 0 & 0 & 0 \\
\hline
\end{tabular}




\begin{tabular}{|c|c|c|c|c|c|c|c|c|c|}
\hline \multirow[t]{3}{*}{ Espécies } & \multirow[t]{3}{*}{$\begin{array}{l}\text { Forma } \\
\text { de vida }\end{array}$} & \multicolumn{6}{|c|}{$\begin{array}{cc} & \text { Formações } \\
\text { herbáceas } & \text { arbustivas }\end{array}$} & \multirow{2}{*}{\multicolumn{2}{|c|}{ florestais }} \\
\hline & & & & \multicolumn{2}{|c|}{ fechadas } & \multicolumn{2}{|c|}{ abertas } & & \\
\hline & & 1 & 2 & 3 & 4 & 5 & 6 & 7 & 8 \\
\hline Hadrolaelia grandis (Lindl. \& Paxton) Chiron \& V. P. Castr & ro HOL & 0 & 0 & 0 & 0 & 0 & 0 & 1 & 0 \\
\hline Koellensteinia altissima Pabst & TER & 0 & 0 & 0 & 0 & 1 & 1 & 1 & 1 \\
\hline Malaxis parthonii Morren & TER & 0 & 0 & 0 & 0 & 0 & 0 & 1 & 0 \\
\hline Mesadenella cuspidata (Lindl.) Garay & TER & 0 & 0 & 0 & 0 & 0 & 0 & 1 & 0 \\
\hline Notylia pubescens Lindl. & HOL & 0 & 0 & 0 & 0 & 1 & 1 & 1 & 0 \\
\hline Octomeria alpina Barb. Rodr. & HOL & 0 & 0 & 0 & 0 & 0 & 0 & 1 & 0 \\
\hline Oeceoclades maculata (Lindl.) Lindl. & TER & 0 & 0 & 0 & 0 & 1 & 1 & 1 & 1 \\
\hline Oncidium baueri Lindl. & $\mathrm{EPF}$ & 0 & 0 & 0 & 0 & 0 & 1 & 1 & 0 \\
\hline Oncidium ciliatum Lindl. & HOL & 0 & 0 & 1 & 1 & 1 & 1 & 1 & 1 \\
\hline Oncidium pumilum Lindl. & HOL & 0 & 0 & 0 & 0 & 0 & 0 & 1 & 0 \\
\hline Paradisanthus micranthus (Barb. Rodr.) Schltr. & TER & 0 & 0 & 0 & 0 & 0 & 0 & 1 & 1 \\
\hline Pelexia maculata Rolfe & TER & 0 & 0 & 0 & 0 & 0 & 0 & 1 & 1 \\
\hline Pleurothallis aquinoi Schltr. & HOL & 0 & 0 & 0 & 0 & 0 & 0 & 1 & 0 \\
\hline Pleurothallis auriculata Lindl. & HOL & 0 & 0 & 0 & 0 & 0 & 0 & 1 & 0 \\
\hline Pleurothallis grobyi Bateman ex Lindl. & HOL & 0 & 0 & 0 & 0 & 0 & 0 & 1 & 0 \\
\hline Pleurothallis obovata (Lindl.) Lindl. & $\mathrm{HOL}$ & 0 & 0 & 0 & 0 & 0 & 0 & 1 & 0 \\
\hline Pleurothallis pristeoglossa Rchb. f \& Warm. & HOL & 0 & 0 & 0 & 0 & 0 & 1 & 1 & 0 \\
\hline Pleurothallis saundersiana Rchb. f. & HOL & 0 & 0 & 0 & 0 & 0 & 1 & 1 & 0 \\
\hline Polystachya concreta (Jacq.) Garay \& Sweet. & HOL & 0 & 0 & 0 & 0 & 0 & 0 & 1 & 0 \\
\hline Prescottia aff. oligantha (Sw.) Lindl. & TER & 0 & 0 & 0 & 0 & 1 & 1 & 1 & 1 \\
\hline Prescottia plantaginea Lindl. & TER & 0 & 0 & 0 & 0 & 1 & 1 & 1 & 0 \\
\hline Prescottia stachyodes Lindl. & TER & 0 & 0 & 0 & 0 & 0 & 0 & 1 & 0 \\
\hline Prosthechea fragrans (Sw.) W. E. Hinggis & $\mathrm{EPF}$ & 0 & 0 & 0 & 0 & 0 & 0 & 1 & 0 \\
\hline Prosthechea pygmaea (Hook.) W. E. Hinggis & HOL & 0 & 0 & 0 & 0 & 0 & 0 & 1 & 0 \\
\hline Pseudolaelia vellozicola C. Porto \& Brade & $\mathrm{EPF}$ & 0 & 0 & 0 & 0 & 0 & 1 & 0 & 0 \\
\hline Rauhiella silvana Toscano & HOL & 0 & 0 & 0 & 0 & 0 & 0 & 1 & 0 \\
\hline Sacoila lanceolata (Aubl.) Garay & TER & 0 & 0 & 1 & 1 & 0 & 0 & 1 & 0 \\
\hline Sarcoglottis fasciculata (Vell.) Schltr. & TER & 0 & 0 & 0 & 0 & 0 & 0 & 1 & 0 \\
\hline Sobralia sp. nov. & TER & 0 & 0 & 0 & 0 & 0 & 0 & 1 & 0 \\
\hline Sobralia liliastrum Lindl. & TER & 0 & 0 & 0 & 0 & 1 & 0 & 0 & 0 \\
\hline Sobralia sessilis Lindl. & TER & 0 & 0 & 0 & 0 & 0 & 0 & 1 & 0 \\
\hline Sophronitis cernua Lindl. & $\mathrm{HOL}$ & 0 & 0 & 0 & 0 & 0 & 0 & 1 & 0 \\
\hline Trichocentrum fuscum Lindl. & HOL & 0 & 0 & 0 & 0 & 0 & 0 & 1 & 0 \\
\hline Vanilla bahiana Hoehne & HEM & 1 & 0 & 1 & 1 & 1 & 1 & 1 & 1 \\
\hline Vanilla chamissonis Klotzsch ex Cogn. & HEM & 0 & 0 & 0 & 0 & 1 & 1 & 1 & 0 \\
\hline Xylobium colley (Bateman ex. Lindl.) Rolfe & EPF & 0 & 0 & 0 & 0 & 0 & 1 & 0 & 0 \\
\hline Zygopetalum intermedium Lodd. & $\mathrm{EPF}$ & 0 & 0 & 0 & 0 & 1 & 1 & 0 & 1 \\
\hline Número total de espécies & & 2 & 3 & 12 & 10 & 20 & 31 & 58 & 14 \\
\hline
\end{tabular}


substrato, crescendo preferencialmente sob as condições ambientais específicas impostas pelo forófito.

Nas restingas do Espírito Santo, para as formações abertas do Litoral Central/Sul, ocorre uma preferência dos holoepífitos por Neomitranthes obtusa Sobral et Zambom (Myrtaceae), enquanto que para as mesmas espécies do Litoral Norte não foi observada preferência para nenhum forófito.

Segundo Fontoura et al. (1997), este tipo de preferência está relacionado às características fisico-mecânicas do ritidoma (baixa dureza, espessura considerável, alta permeabilidade e presença de fissuras mais ou menos profundas). Para as espécies da floresta arenosa litorânea, que contempla o maior numero de espécies holoepífitas, não foi observada nenhuma preferência das espécies quanto à espécie do forófito.

As vantagens proporcionadas pelo epifitismo são as melhores condições de luminosidade e substrato relativamente isento de competição (Waechter, 1986). No entanto ocorrem flutuações na disponibilidade de água, normalmente oriunda do ar atmosférico, carregada de nutrientes necessários para o desenvolvimento da planta (Nadkarni, 1986), o que pode alterar as condições ideais para a relação holoepífito/forófito.

O epifitismo foi um mecanismo de especiação à procura de melhores habitats (Benzing, 1981; 1987), o que propiciou expansão para a família Orchidaceae, originando um significativo aumento de diversidade nas florestas tropicais.

Segundo Gentry \& Dodson (1987), cerca de 29 mil espécies são epífitas em todo o mundo, o que corresponde a cerca de $10 \%$ de todas as plantas vasculares, porém poucas famílias de plantas tiveram grande sucesso e irradiaram-se como epífitas. Nas epífitas vasculares, $80 \%$ estão concentrados em apenas quatro famílias: Orchidaceae, Bromeliaceae, Polypodiaceae e Araceae, podendo constituir $1 / 3$ de todas as espécies de plantas vasculares em uma área ou $63 \%$ dos indivíduos de plantas vasculares, evidenciando sua grande contribuição à florística e fitossociologia de algumas florestas tropicais.

Para as Orchidaceae terrestres da restinga do Espírito Santo observa-se um relacionamento com as subfamílias, sendo duas espécies de Vanilloideae, todas as Orchidoideae (14) e 12 espécies de Epidendroideae. Segundo Dressler (1981) os gêneros que representam as subfamílias Vanilloideae e Orchidoideae (sensu Cameron, 1999) são predominantemente terrestres em todo o mundo, com poucas exceções.

Embora na maioria dos gêneros de Epidendroideae o epifitismo seja predominante, alguns gêneros desta subfamília retornaram à forma de vida terrestre em virtude de modificações ambientais pretéritas (Barros, 1990).

$\mathrm{O}$ ambiente terrestre, no ecossistema restinga, apresenta uma grande diferença quanto a exposição à luz e ao alagamento, podendo o sedimento ser encontrado totalmente exposto, coberto por serapilheira ou por água. As Orchidaceae que colonizam os sedimentos da restinga acabam por ter um amplo conjunto de ambientes. Os ambientes com grande disponibilidade de luz e água possibilitam a vida de espécies heliófilas higrófilas, como as ocorrentes em áreas da formação brejo herbáceo. Espécies que necessitam de uma menor disponibilidade de água, mas também são heliófilas, são encontradas na formação aberta de Ericaceae, sazonalmente alagada.

Outro grupo de espécies que vivem em ambientes com grande disponibilidade de luminosidade é formado por espécies heliófilas não higrófilas, comuns na região de entre moitas nas formações arbustivas abertas e em formações arbustivas fechadas, quando não apresentam grandes alturas para sombreamento, como observado por Fraga \& Pereira (1998) para a formação pós-praia do Espírito Santo.

Para o grupo de espécies que não se desenvolvem diretamente expostas ao sol 
(esciófilas), a presença de água próximo ao sedimento possibilita que algumas espécies instalem-se ao longo das restingas do Espírito Santo, como observado por Pereira (1990a) e Fabris (1995). No entanto, nenhuma espécie apresenta-se restrita às regiões com pouca luminosidade e com grande disponibilidade de água das formações florestais periodicamente ou permanentemente inundadas.

Há espécies que, além de se desenvolverem em florestas periodicamente inundadas, também foram detectadas na floresta arenosa litorânea e em formações arbustivas abertas, no interior das moitas.

As espécies terrestres esciófilas não higrófilas vegetam normalmente no interior da floresta arenosa litorânea. Dentre estas, entretanto, algumas são comuns às formações arbustivas fechadas ou ao interior das moitas das formações arbustivas abertas, que possibilitam um micro ambiente propício para o desenvolvimento destas espécies.

As espécies epífitas facultativas são encontradas sobre um forófito ou sobre o solo arenoso, quando caem e sobrevivem nesta condição ou quando aí germinam e sobrevivem. Normalmente, estas espécies possuem estruturas para se desenvolverem como holoepifítas. Nas restingas do Espírito Santo as espécies desta forma de vida foram coletadas como holoepifítas e terrestres ou citadas na literatura como holoepífitas e coletadas nas restingas do Estado somente como terrestres.

As espécies epífitas facultativas das restingas do Espírito Santo são preferencialmente epífitas em Floresta Atlântica de Encosta e em Floresta de Tabuleiro (Fraga, 2000), ocorrendo nas formações arbustivas das restingas do Estado em ambas as formas de vida (holoepífita e terrestre) e sendo preferencialmente holoepífitas em formações florestais.

As hemiepífitas são representadas por espécies de Vanilla, que estabelecem relação temporária com o forófito por germinarem como terrestre, passando a escalar o forófito, e perdendo posteriormente o contato com o solo, como já observado por Waechter (1998) para planície costeira sul-rio-grandense.

Nas restingas do Espírito Santo, Vanilla chamissonis apresenta uma forma de vida mais próxima ao holoepifitismo, por encontrarse normalmente bem aderida ao caule através de seu sistema radicular, enquanto $V$. bahiana encontra-se mais livre dos caules do forófito, normalmente crescendo sobre pequenos arbustos junto a sua copa, similar ao comportamento de espécies escandentes de outras famílias botânicas.

\section{Similaridade florística das formações da restinga do Estado do Espírito Santo.}

Das 10 formações vegetais encontradas nas restingas do Espírito Santo a família Orchidaceae foi coletada em oito, classificadas em ordem de importância quanto ao número de táxons, em floresta arenosa litorânea (58), formação aberta de Clusia (31), formação aberta de Ericaceae (20), floresta periodicamente inundada (14), formação póspraia (13), formação Palmae (10), formação brejo herbáceo (3) e formação praial graminóides (2). As formações halófilapsamófila e floresta permanentemente inundada são desprovidas de espécies de Orchidaceae (Tabela 1).

Em relação à distribuição pelas formações de restinga do Estado, Vanilla bahiana é a espécie com maior distribuição, ocorrendo em sete formações, seguida por Eltroplectris calcarata e Oncidium ciliatum que ocorrem em seis.

A partir da presença/ausência das Orchidaceae, em uma ou mais formações, obteve-se o dendograma de similaridade florística (Figura 3), que apresentou uma correlação cofenética satisfatória acima de 0,9 .

Para auxiliar a visualização dos grupos de espécies que mais influenciaram na união entre as diversas formações tratadas na figura 3 , optou-se por apresentar nas figuras 4, 5 e 6 os dendogramas de similaridade, entre as formações e as espécies de cada tipo de forma 


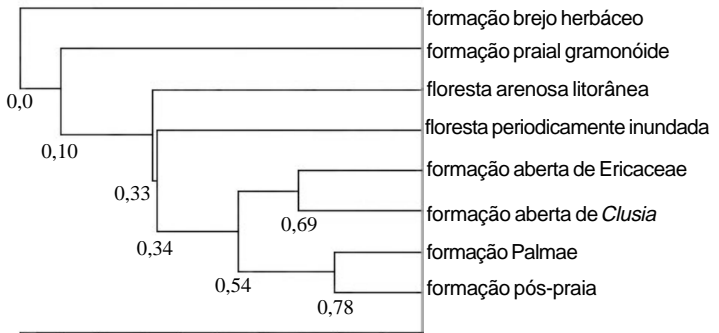

$\begin{array}{llllllllllll}0,0 & 0,1 & 0,2 & 0,3 & 0,4 & 0,5 & 0,6 & 0,7 & 0,8 & 0,9 & 1,0\end{array}$

Figura 3- Similaridade florística entre as diversas formações das restingas do litoral do Espírito Santo, com base nas espécies de Orchidaceae (Correlação cofenética $=0,9416$ ).

de vida (terrestre, holoepífito e epífito facultativo). As correlações cofenéticas foram satisfatórias, estando acima de 0,78 para todos os dendogramas.

Para as espécies terrestres, o dendograma (Figura 4) está baseado em todas as comunidades analisadas na figura 3 , enquanto nos dendogramas exclusivos para as espécies holoepífitas (Figura 5) e epífitas facultativas (Figura 6), as formações herbáceas e formações herbáceas, juntamente com a formação Palmae, respectivamente, não foram consideradas na análise em função da inexistência de espécies destas formas de vida nestas formações.

Com base no dendograma (Figura 3), pode-se observar que a maior similaridade encontra-se entre a formação pós-praia e formação Palmae, em função de estarem no primeiro cordão arenoso, a uma mesma

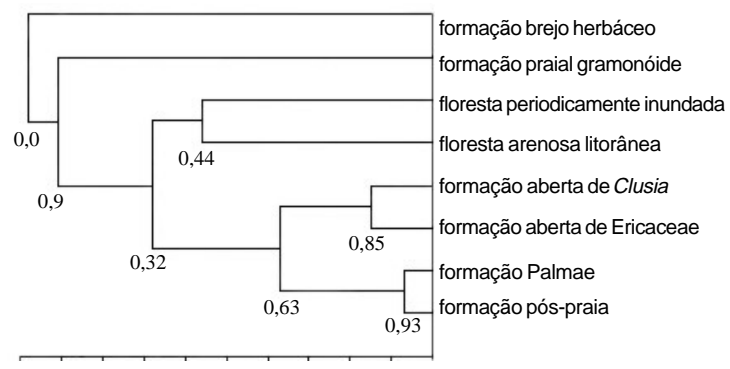

$\begin{array}{lllllllllll}0,0 & 0,1 & 0,2 & 0,3 & 0,4 & 0,5 & 0,6 & 0,7 & 0,8 & 0,9 & 1,0\end{array}$

Figura 4- Similaridade florística entre as diversas formações das restingas do litoral do Espírito Santo, com base nas espécies de Orchidaceae terrestres (Correlação cofenética $=0,9458$ ). distância da linha de praia, ao longo de todo litoral do Estado. Segundo Pereira (1990a), estas formações mantêm-se, em média, a uma mesma distância do lençol freático, o que propicia uma umidade semelhante ao sedimento para as duas formações, além de estarem sujeitas mais diretamente ao vento carregado de salinidade (Pereira, 1990a).

Nas formações arbustivas fechadas (formação pós-praia e formação Palmae) predominam espécies terrestres, sendo Campylocentrum micranthum e Oncidium ciliatum as únicas holoepífiticas. Segundo Fraga \& Pereira (1998) o pequeno porte das plantas lenhosas é um fator limitante ao estabelecimento de determinadas espécies holoepifíticas de Orchidaceae, como evidenciado pelo aumento significativo no escore de similaridade quando analisadas somente as espécies terrestres (Figura 4), e pela diminuição do escore quando analisadas somente espécies holoepífitas características (Figura 5).

As formações arbustivas abertas de Ericaceae e de Clusia ligam-se entre si e, posteriormente, ligam-se às formações arbustivas fechadas, com escores acima de $50 \%$ de similaridade, formando um grupo exclusivo de formações arbustivas.

A ligação entre as formações abertas de Ericaceae e de Clusia, unidades fisionômicas semelhantes, formadas por moitas circulares e uma região aberta com sedimento aparente,

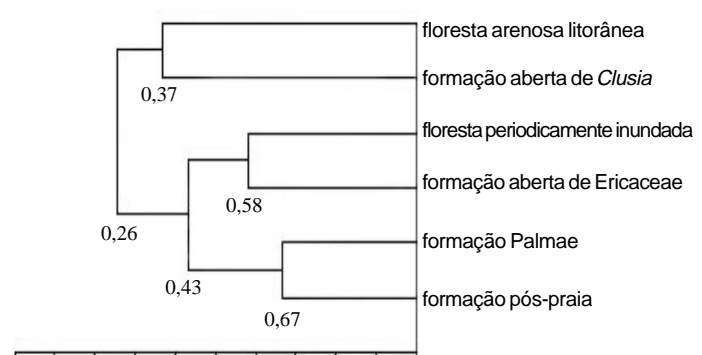

$\begin{array}{lllllllllll}0,0 & 0,1 & 0,2 & 0,3 & 0,4 & 0,5 & 0,6 & 0,7 & 0,8 & 0,9 & 1,0\end{array}$

Figura 5- Similaridade florística entre as diversas formações das restingas do litoral do Espírito Santo, com base nas espécies de Orchidaceae holoepífitas (Correlação cofenética $=0,7958$ ) 


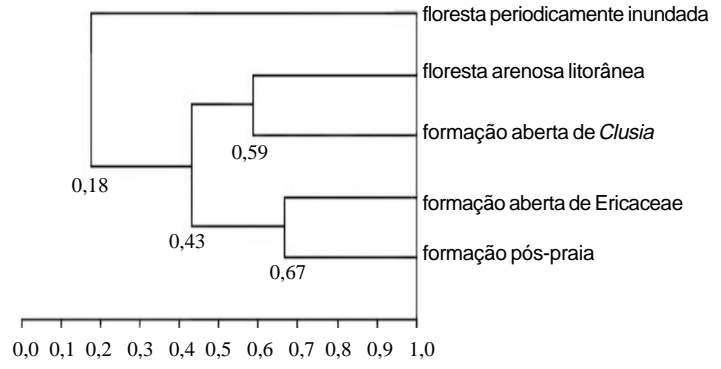

Figura 6- Similaridade florística entre as diversas formações das restingas do litoral do Espírito Santo, com base nas espécies de Orchidaceae epífitas facultativas (Correlação cofenética $=0,7871$ ).

é garantida principalmente pelas espécies terrestres, ficando evidenciada pelo aumento significativo no escore da similaridade entre estas formações, quando analisadas somente as espécies terrestres (Figura 4), sendo esta a única forma de vida em que as duas formações se mantêm ligadas (Figura 4, 5 e 6).

As espécies terrestres heliófilas da região de borda de moita e de entre moitas são bastante similares entre as duas formações arbustivas abertas, onde as espécies Catasetum discolor, Cyrtopodium polyphyllum, C. holstii, Epidendrum denticulatum e Prescottia plantaginea se distribuem em ambas as formações. Sobralia liliastrum, presente somente na formação aberta de Ericaceae, e Epidendrum secundum, presente apenas em regiões antropizadas da formação aberta de Clusia em Setiba (Gurapari), foram as únicas espécies terrestres heliófilas dissimilares entre as duas formações.

Estas espécies terrestres heliófilas da região de borda de moita e de entre moitas parecem estar mais ligadas à luminosidade que à disponibilidade de água, por distribuirem-se de forma similar nas formações aberta de Ericaceae e aberta de Clusia, como já salientado por Pereira \& Araújo (1995) e Pereira (1990b) para a maioria das espécies vegetais das regiões de entre moitas, mesmo que na formação aberta de Ericaceae, o lençol freático chegue em determinadas épocas do ano bem próximo da superfície, alterando a disponibilidade de água no sedimento.

Rodriguésia 55 (84): 5-20. 2004
Para as Orchidaceae terrestres esciófilas, de interior de moitas, também se observa que a maioria das espécies encontrase distribuída em ambas as formações abertas, tais como Eltroplectris calcarata, E. triloba, Habenaria leptoceras, Koelensteinia altissima, Oeceoclades maculata, Prescottia aff. oligantha e Zygopetalum intermedium, sendo apenas Cleistes revoluta $\mathrm{e}$ Episthephium lucidum favorecidas pela maior disponibilidade de água no sedimento, presentes somente na formação aberta de Ericaceae.

Embora as grandes moitas apresentem micro-habitat que possibilitam o recrutamento de espécies que não seriam capazes de suportar condições mais severas, encontradas em áreas desnudas (Zaluar \& Scarano, 2000), somente poucas espécies de habitat umbrófilos conseguem utilizar os microhabitat criados pela sombra das moitas, ocasionando uma maior diversidade de espécies terrestres esciófilas, comuns entre as duas formações florestais, em relação àquelas comuns entre as formações florestais e arbustivas (Figura 4).

A formação aberta de Clusia detém maior diversidade de espécies do que a formação aberta de Ericaceae, estando todas as holoepífitas da formação aberta de Ericaceae presentes na formação aberta de Clusia. Quando analisadas somente as espécies holoepífitas (Figura 5), verifica-se que as formações abertas de Clusia e de Ericaceae separam-se, ficando ligadas com a floresta arenosa litorânea e a floresta periodicamente inundada, respectivamente. Este fato vem a contribuir para baixar o escore de similaridade entre as formações arbustivas abertas, porém não sendo suficiente para separá-las na análise geral (Figura 3).

Entre a formação aberta de Clusia e floresta arenosa litorânea observa-se um número expressivo de espécies holoepífitas comuns (Campylocentrum aciculatum, C. micranthum, Cyrtopodium gigas, Notylia pubescens, Oncidium ciliatum, Pleurothallis 
pristeoglossa, $P$. saundersiana), porém, em virtude de uma maior riqueza de espécies holoepífitas na floresta arenosa litorânea, o escore manteve-se baixo. Entre a formação aberta de Ericaceae e a floresta periodicamente inundada, a única espécie comum desta forma de vida é Oncidium ciliatum, sendo, neste caso, a ausência de espécies holoepífitas que se apresenta similar entre as formações.

A proximidade ao lençol freático não representa um fator importante na seleção das espécies holoepífitas das formações arbustivas abertas e florestais, embora este fator deva ser importante na seleção dos forófitos arbóreos, justificando a presença/ausência de diferentes forófitos em áreas inundáveis e em áreas não inundáveis. Características como estas podem ser observadas na análise das espécies epífitas facultativas (Figura 6), onde a formação aberta de Clusia e floresta arenosa litorânea se ligam. Estas espécies epífitas facultativas, no entanto, encontramse como holoepífitas e terrestres em formações arbustivas, e preferencialmente holoepífitas em formações florestais. As espécies Brassavola tuberculata, Cattleya gutatta, C. harrisoniana, E. latilabrum e Oncidium baueri, enquadram-se neste tipo de forma de vida.

O grupo de formações arbustivas manteve uma ligação com a floresta periodicamente inundada em níveis inferiores a $50 \%$, ligando-se, posteriormente, com a floresta arenosa litorânea (Figura 3). A ligação do grupo de formações arbustivas com a floresta periodicamente inundada ficou reforçada pela presença de Eltroplectris calcarata, Episthephium lucidum, Koellensteinia altissima, Oeceoclades maculata, Oncidium ciliatum, Prescottia aff. oligantha e Zygopetalum intermedium, espécies distribuídas tanto no interior de moitas mais sombrias como na floresta periodicamente inundada.

O escore de ligação do grupo formado pelas formações arbustivas e floresta periodicamente inundada com a floresta arenosa litorânea é mantido baixo (Figura 3), em virtude da maior riqueza de espécies na floresta arenosa litorânea e de espécies exclusivas a esta formação vegetal que acabam por representar ausências nas demais formações analisadas.

$\mathrm{Na}$ análise que enfoca somente as espécies terrestres (Figura 4) observa-se que as duas formações florestais (floresta periodicamente inundada e floresta arenosa litorânea) encontram-se unidas entre si, e não unidas com as comunidades abertas mais similares em relação à disponibilidade de água (aberta de Ericaceae e aberta de Clusia, respectivamente). Esta ligação fica reforçada pela presença de espécies como Beadlea elegans, Paradisanthus micranthus e Pelexia maculata, exclusivas de áreas com pouca disponibilidade de luz destas duas formações.

$\hat{A}$ medida que as florestas passam a apresentar um dossel mais aberto, começam a aparecer outras espécies, sendo então favorecidas as espécies amplamente distribuídas nas formações das restingas do Estado e na maioria das vezes tolerantes a uma maior luminosidade, como Eltroplectris calcarata, E. triloba, Epidendrum latilabrum, Habenaria leptoceras, Koellenteinia altissima, Oeceoclades maculata, Prescottia aff. oligantha e $P$. plantaginea encontradas também em regiões mais abrigadas ou no interior das formações arbustivas fechadas e abertas.

Um outro fator que contribuiu para a ligação das formações arbustivas abertas e formações florestais foi a presença de três espécies terrestres heliófilas, típicas de regiões abertas (Cyrtopodium polyphyllum, Prescottia plantaginea e Sacoila lanceolata) em algumas áreas de floresta degradada ao Norte do Estado, que foram incluídas no cálculo da similaridade.

As formações arbustivas e florestais ligam-se com baixos escores às formações herbáceas (inicialmente praial-graminóide e 
posteriormente brejo herbáceo), que apresentam vegetação diretamente exposta ao sol, não possibilitando a ocorrência de holoepifitismo ou de espécies esciófilas (Figura 3 e 4).

A formação praial-graminóide não revelou semelhança com qualquer outra formação isoladamente, mas sim uma similaridade em nível de $10 \%$ com todas em conjunto. Esta formação localiza-se, segundo Pereira (1995), entre as formações halófilapsamófila (sensu Thomaz, 1994) e formação aberta de Clusia em Regência, município de Linhares, não ocorrendo em outro ponto do litoral do Espírito Santo. As únicas espécies determinadas para esta formação foram Catasetum discolor e Vanilla bahiana, sendo as duas espécies também comuns a outras formações de restinga. Segundo Fraga (2000), estas espécies apresentam ampla distribuição ao longo da restinga do Espírito Santo.

A formação brejo herbáceo também não se liga a qualquer outra unidade isoladamente, encontrando-se dissimilar ao conjunto de todas as demais formações (Figura 3,4). Diferente do que ocorre com a composição florística da formação praial-graminóide, as espécies nesta formação são exclusivas (Habenaria fastor, $H$. parviflora e $H$. repens), levando o escore de ligação a $0 \%$, pois só ocorrem em ambientes heliófilos e com grande disponibilidade de água, e, segundo Hoehne (1940), como a maioria das espécies deste gênero.

\section{AGRADECIMENTOS}

Ao CNPq pela bolsa de Mestrado. Às Instituições: Fundação $O$ Boticário de Proteção à Natureza (FBPN), The John D. and Catherine T. MacArthur Foudation, WWF (Fundo Mundial para a Natureza) e USAID (United States Agency for International Development, que financiaram o projeto. A Helio de Queiroz Boudet Fernandes diretor do Museu de Biologia Prof. Mello Leitão e Curador do Herbário MBML, por ceder a estrutura do Museu para o término da pesquisa. À coordenação do
Curso de Pós-Graduação de Botânica do Museu Nacional - UFRJ. Aos curadores dos herbários consultados. A Fábio de Barros e Antônio Toscano de Brito, pelo auxílio na identificação de diversas espécies. A Luciano de Bem Bianchetti e João Aguiar Nogueira Batista pela ajuda na identificação de Cyrtopodium e Habenaria respectivamente. A Dorothy Araujo pela correção do abstract. A Mariana Machado Saavedra pelo auxílio na correção final deste artigo.

\section{REFERÊNCIAS BIBLIOGRÁFICAS}

Araújo, D. S. D. \& Henriques, R. P. B. 1984. Análise florística das restingas do Estado do Rio de Janeiro. In: Lacerda, L. D.; Araujo, D. S. D.; Cerqueira, R. \& Turcq, B. (orgs.) Restinga: origem, estrutura e processo. Niterói, CEUFF, p. 151-193.

Barros, F. 1990. Diversidade taxonômica e distribuição das Orchidaceae brasileiras. Acta botanica brasilica 4 (1): 177- 187.

Benzing, D. H. 1981. Bark surfaces and the origin and maintenance of diversity among angiosperm epiphytes: a hypothesis. Selbyana 5: 248-255.

. 1986. The vegetative basis of vascular epiphytism. Selbyana 9: 23-43.

1987. Vascular epiphytism: taxonomic participation and adaptative diversity. Annals of the Missouri Botanical Garden 74: 183-204.

Breier, T. B. 1999. Florística e ecologia de epífitos vasculares em uma floresta costeira do sul do Brasil. Porto Alegre, Universidade Federal do Rio Grande do Sul. Dissertação de Mestrado. 83 p.

Cameron, K. M.; Chase, M. W.; Whitten, W. M.; Kores, P. J.; Jarrell, D. C. Albert, V. A.; Yukawa, T.; Hills, H. G. \& Dgoldman, D. H. 1999. A phylogenetic analysis of the Orchidaceae: evidence from $r b c L$ nucleotide sequences. American Journal of Botany 86 (2): 208-224. 
Cardoso, M. S. R. 1995. Análise fitossociológica na formação Palmae de restinga no Parque Estadual Paulo César Vinha - Guarapari/ES. Vitória, Universidade Federal do Espírito Santo. Monografia de Especialização. 67 p.

Dressler, R. L. 1981. The Orchids: natural history and classification. Harvard, Harvard University Press. 332 p.

Fabris, L. C. 1995. Composição florística e fitossociológica de uma faixa de floresta arenosa litorânea do Parque Estadual de Setiba, município de Guarapari, ES. Rio Claro, Universidade de São Paulo. Dissertação de mestrado. 195 p.

\& Pereira, O. J. 1994. Levantamento florístico na formação Pós-praia, na restinga de Setiba, Município de Guaraparí, ES. In: III Simpósio de ecossistemas da costa Sul e Sudeste brasileira: subsídios a um gerenciamento ambiental. Serra Negra, ACIESP (org.), vol.3, p. 124-133.

Fagnani, M. P. K. \& Siqueira, C. I. S. 1998. Orquídeas da restinga de Massambaba. In: Atas da $15^{a}$ Conferência Mundial de Orquídeas. Turries, France, Naturalia Publications. p. 293-296.

Fontoura, T.; Sylvestre, L. S.; Vaz, A. M. S. F. \& Vieira, C.M. 1997. Epífitos vasculares, hemiepífitos e hemiparasitas da reserva ecológica de Macaé de Cima. In: Lima, H. C. \& Guedes-Bruni, R. R. (eds.) Serra de Macaé de Cima: Diversidade florística e conservação em Mata Atlântica. Rio de Janeiro, p. 89-101.

Fraga, C. N. 2000. Ecologia, fitogeografia e conservação das Orchidaceae das restingas do Estado do Espírito Santo. Rio de Janeiro, Universidade Federal do Rio de Janeiro. Dissertação de mestrado. $170 \mathrm{p}$.

\& Pereira, O. J. 1998. Orchidaceae da comunidade pós-praia das restingas do Estado do Espírito Santo. Caderno de Pesquisa da UFES 8: 65-72.
Gentry, A. \& Dodson, C. H. 1987. Diversity and biogeography of neotropical vascular epiphytes. Annals of the Missouri Botanical Garden 74: 205-233.

Hoehne, F. C. 1940. Orchidaceae. In: Flora brasilica, Hoehne, F. C. (ed.), v.12, part.1, p. 1-254.

Martin, L.; Suguiu, K.; Domingues, J. M. L. \& Flexor, J. 1997. Geologia do Quaternário costeiro do Litoral Norte do Rio de Janeiro e Espírito Santo. Belo Horizonte, CPRM. 112 p.

Mori, S. A.; Silva, L. A. M.; Lisboa, G. \& Coradini, L. 1989. Manual de manejo do herbário fanerogâmico. Ilhéus, Centro de Pesquisa do Cacau, 104 p.

Mota, E. V. R. 1991. Identificação de novas unidades de conservação no Estado do Espírito Santo utilizando o Sistema de Análise Geo-Ambiental/SAGA. Viçosa, Universidade Federal de Viçosa. Dissertação de mestrado. 140 p.

Mueller-Dombois, D. \& Ellenberg, H. 1974. Aims and methods of vegetation ecology. New York, J. Wiley e Sons Press. 547 p.

Nadkarni, N. M. 1986. The nutritional effects of epiphytes on host trees with special references to alteration of precipitation chemistry. Selbyana 9: 44-55.

Pereira, O. J. 1990a. Caracterização fitofisionômica da restinga de Setiba Guarapari/ES. In: II Simpósio de ecossistemas da costa Sul e Sudeste brasileira: estrutura, função e manejo. Águas de Lindóia, ACIESP (org.), vol.3, p. 207-219.

. 1990b. Levantamento florístico e fitossociológico de uma área de restinga do Espírito Santo. Rio de Janeiro, Universidade Federal do Rio de Janeiro. Dissertação de mestrado. 158 p.

\& Araújo, D. S. D. 1995. Estrutura da vegetação de entre moitas da formação aberta de Ericaceae no Parque 
Estadual de Setiba, ES. Oecologia brasiliensis 1: 245-257.

\& Araújo, D. S. D. 2000. Análise florística das restingas dos Estados do Espírito Santo e Rio de Janeiro. In: Esteves, F.A. \& Lacerda, L.D. (eds.). Ecologia de Restingas e Lagoas Costeiras. Rio de Janeiro, NUPEM/ UFRJ, p. 25-63.

\& Assis, A.M. 2000. Florística da restinga de Camburí, Vitória, ES. Acta botanica brasilica 14 (1): 99-111.

\& Gomes, J. M. L. 1994. Levantamento florístico das comunidades vegetais de restinga no Município de Conceição da Barra, ES. In: III Simpósio de ecossistemas da costa Sul e Sudeste Brasileira: subsídios a um gerenciamento ambiental. Serra Negra, ACIESP (org.), vol.3, p. 67-78.

\& Zambom, O. 1998. Composição florística da restinga de Interlagos, Vila Velha (ES). In: IV Simpósio de ecossistemas da costa Sul e Sudeste brasileira. Águas de Lindóia, ACIESP (org.), vol.3, p. 129-139.

; Assis, A.M. \& Souza, R.L.D. 1998. Vegetação da restinga de Pontal do Ipiranga, município de Linhares, ES. In: IV Simpósio de ecossistemas da costa Sul e Sudeste brasileira. Águas de Lindóia, ACIESP (org.), vol.3, p. 117-128.

; Thomaz, L. D. \& Araujo, D. S. D. 1992. Fitossociologia da vegetação de ante-dunas da restinga de Setiba/ Guarapari e em Interlagos/Vila Velha; ES. Boletim do Museu de Biologia Prof. Mello Leitão (Nov. Sér.) 1: 65-75.

Pereira, S. V. 1995. Análise fitossociológica nas formações halófila, psamófila e praial graminóide com arbustos na restinga da Reserva Biológica de Comboios/ Linhares (ES). Vitória, Universidade Federal do Espírito Santo. Monografia de Especialização. 54 p.
Putz, F. E. \& Holbrook, N. M. 1986. Notes on natural history of hemiepiphytes. Selbyana 9: 61-69.

Ribeiro, J. E. L. S. \& Monteiro, R. 1994. Diversidade das orquídeas (Orchidaceae) da Planície Litorânea da praia da fazenda (Vila de Picinguaba, município de Ubatuba, SP) e ocorrência no litoral brasileiro. In: III Simpósio de ecossistemas da costa Sul e Sudeste Brasileira: subsídios a um gerenciamento ambiental. Serra Negra, ACIESP (org.), vol.3, p. 99-106.

Ruschi, A. 1950. Fitogeografia do Estado do Espírito Santo. Considerações gerais sobre distribuição da flora no Estado do Espírito Santo. Boletim do Museu de Biologia Prof. Mello Leitão 1: 1-153. 1979. As restingas do Estado do Espírito Santo. Boletim do Museu de Biologia Prof. Mello Leitão 91: 1-41. 1986. Orquídeas do Estado do Espírito Santo. Rio de Janeiro, Expressão e Cultura, $278 \mathrm{p}$.

Shepherd, G.J. 1984. Fitopac 1: Manual do Usuário. Campinas, Unicamp. 88 p.

Suguio, K. \& Martin, L. 1990. Geomorfologia das restingas. In: II Simposio de ecossistema da costa Sul e Sudeste brasileira: estrutura, função e manejo. Águas de Lindóia, ACIESP (org.), vol.3, p. 185-205.

Thomaz, L. D. \& Monteiro, R. 1994. Análise florística das comunidades halófilapsamófila das praias do Estado do Espírito Santo. In: III Simpósio de ecossistemas da costa Sul e Sudeste brasileira: Subsídios a um gerenciamento ambiental. Serra Negra, ACIESP (org.), vol.3, p. 58-66.

Ule, E. 1901. Die vegetation von Cabo Frio an der Kuste von Brasilien. Botanische Jahrbucher 28: 511-528.

Waechter, J. L. 1986. Epífitos vasculares da mata paludosa do Faxinal, Torres, Rio 
Grande do Sul, Brasil. Iheringia (Sér.

Bot.) 34: 39-49.

1998. Orquídeas epífitas nos Subtrópicos Orientais da América do Sul. In: Atas da $15^{a}$ Conferência Mundial de Orquídeas. Turries, França, Naturalia Publications, p. 332-341.

Zaluar, H. L. T. \& Scarano, F. R. 2000. Facilitação em restingas de moitas: Um século de busca por espécies focais. In: Esteves, F. A. \& Lacerda, L. D. (eds.). Ecologia de restingas e lagoas costeiras. Rio de Janeiro, NUPEM/ UFRJ, p. 3-23. 